\title{
Landscape Simulation and Visualization on Google Earth
}

\author{
Tsuyoshi Honjo ${ }^{1}$, Kiyoshi Umeki ${ }^{1}$, Darhsiung Wang ${ }^{2}$, Pinan Yang ${ }^{3}$ and Hanching Hsieh ${ }^{2}$ \\ ${ }^{1}$ Chiba University, 648 Matsudo, Matsudo, Chiba, 271-8510, Japan \\ ${ }^{2}$ Taiwan Forestry Research Institute, No. 53, Nan-Hai Road, Taipei, Taiwan, R.O.C. \\ ${ }^{3}$ Southern Taiwan University, N0.1, Nan-Tai Street, Yung-Kang, Taiwan, R.O.C.
}

\begin{abstract}
In this study, we made a landscape visualization system that enables virtual experience in a planned landscape including vegetation on Google Earth. The applicability of the system to the landscape design was quite powerful. The planning system generates KML (Keyhole Markup Language) and VRML. KML file is visualized on Google Earth and VRML file can be visualized on stand alone computer. Plants were automatically placed on a terrain based on the data of GIS or Excel by using the system developed in this study. With the system, we made models of Koishikawa Korakuen Garden based on measured data. Performance of walk-through simulations was quite good. We proved that landscape visualization and simulation with Google Earth was possible and that the system can be used as a practical and low cost landscape simulation tool.
\end{abstract}

Index Terms-GIS, KML, landscape visualization, landscape planning, VRML.

\section{INTRODUCTION}

Google Earth is broadly used by seeing the aerial view and it is also used to show the three dimensional scenery. Because many realistic architectures are placed on city area, virtual experience of walking through streets is possible in some area in the big cities But there are few vegetation models on the Google Earth and it is difficult to experience walk-through in parks. In this study, we made a landscape visualization system that enables virtual experience in a planned landscape including vegetation on Google Earth and the applicability of the system to the landscape design was shown. In landscape planning, utilization of Google Earth will be a powerful tool for public understanding and for selection of alternative planning scenarios.

We have been studying the walk-through simulation in the landscape with the system that used VRML (Virtual Reality Modeling Language) (Honjo and Lim [3], Lim and Honjo [4], Lim et al.[5]). Visualization on Google Earth, which uses KML (Keyhole Markup Language), is achieved with same method in the system of VRML. By using Google Earth or VRML, walk-through simulation is made possible. We can build the virtual reality environment in a personal computer economically.

To make a model of Google Earth, SketchUp is frequently

Manuscript Received on October 26, 2010.

E-mail: honjo@faculty.chiba-u.jp. used. Although SketchUp is useful software, in making a building, it is very difficult to make a park with thousands of trees on the ground. In this study, we developed software, which directly generate a KLM file of huge number of objects in landscapes.

In the computer graphics of landscape simulation, quality of plants plays an important role. Many models were developed and were applied in the area of landscape visualization $[1,2,6,7$, 9]. In this study, we used this modeling technique of plants for the visualization of forests and parks.

\section{METHODS}

\subsection{Google Earth and KML}

With Google Earth, final result of the scene can be stored in the format of KML or KMZ, which describe the three dimensional information of the models. As the KMZ file is only compressed text file of KML with zip format, KMZ has the same information of KML. KML is also a programming language and library for 3-D computer graphics and has many functions. Programming with KML is similar to that of VRML and the same method of Honjo and Lim [3] can be used in the case of KML with Google Earth to develop a visualization system. Because there is freeware version of Google Earth, the developing environment can be built very economically.

To visualize the model described in KML, it is necessary to just click the KML file. Then, Google Earth is automatically executed and the model is shown.

\subsection{Modeling of landscape with KML}

Basic functions for the visualization of landscape are the modeling and setting of plants, terrain, and architecture. Among these elements, modeling of plants are the most difficult function.

About plants, we made a software with which we converts from the plant data to KML format. In an inventory of forests and gardens, species, location of plants or density of plants, height, width and diameter of trunk (usually at breast height) were usually recorded. With the developed system, the data of the inventory are stored in GIS like ArcView (ESRI) or Excel (Microsoft Inc.). The data are converted to KML format and also VRML format (Fig.1). The system for the conversion was 
written in Visual Basic (Microsoft Inc.).

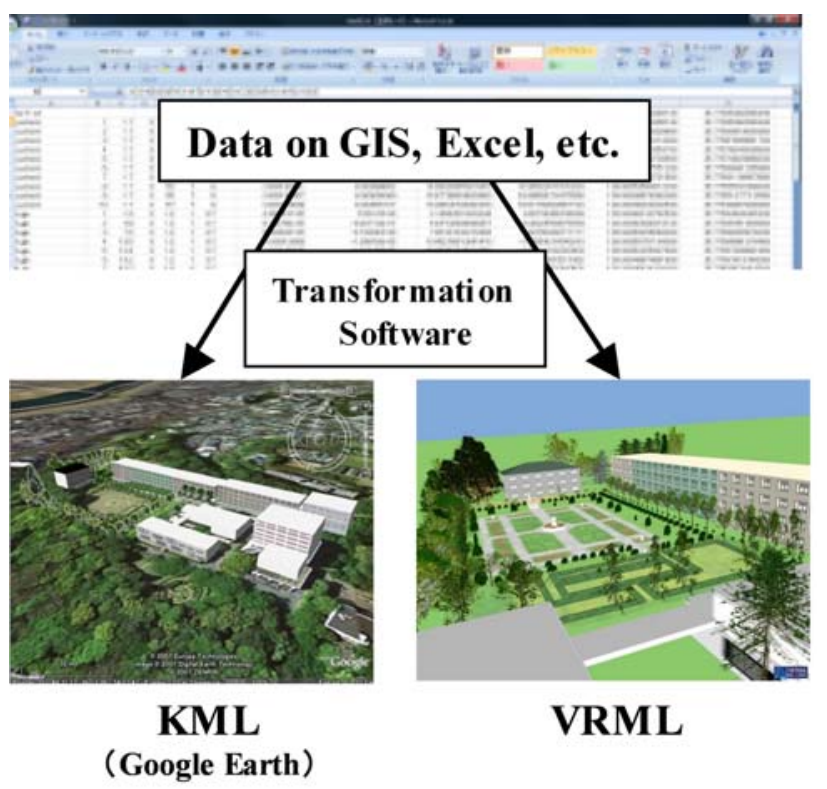

Fig. 1. Transformation of data to VRML or KML

Because Google Earth has the information on terrain or elevation data (DEM) in the software, it is not necessary to prepare a terrain model. The 3-D models of building are also made in the system in some part of city area.

In this study, the model of plants is made with billboard to reduce the numbers of polygons. Two crossed planes were used to express a tree. We used 2-D textures of plant images for 300 species according to the growth stage, which was made from 3-D models of AMAP [2].

Although many progresses in plant modeling have been reported $[10,11,12]$, using the simple billboard is still most practical method in the area of landscape architecture. In the landscape deign, the most important application of VR is showing the rough sketch of the designed landscape to the client or the public by walking through the designed landscape. Reality such as motion of plants is not important. Prediction of the future landscape by the plant growth can be done by AMAP. Google Earth provided this VR feature very effectively.

In Fig 2, the example of the trees is shown. For a landscape simulation that consists of plants at various growth stages, texture images of plants of each growth stages are required. It is difficult to take these photographs and computer graphics images are usually used.

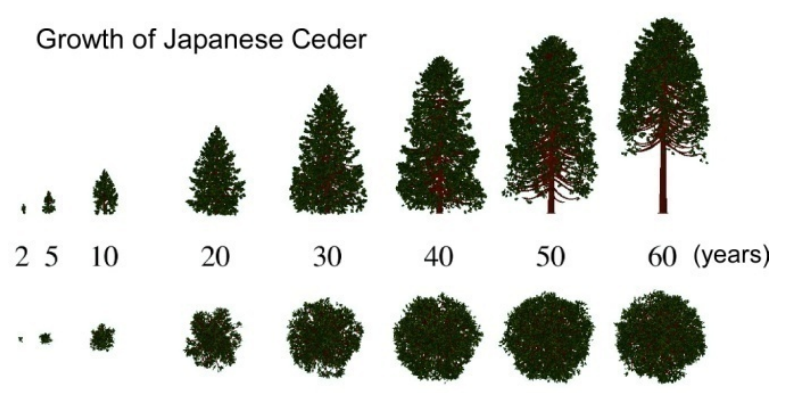

Fig. 2. Example of images of plants in several growth stages.
In this study, more than 3000 2D images (for 300 species and about 10 growth stages for each plants) are prepared.

\subsection{Modeled garden}

In order to show the performance of the system in this study, Koishikawa Korakuen Garden, one of the most famous Japanese gardens, was simulated. The basic data of the garden were mainly taken from a research report on the environment of the garden in 1985 (Tokyo Metropolitan Government and Korakuen Stadium [8]) and growth and changes after the research are taken into account. In the inventory there are 2980 plants with 91 species (the heights were more than $3 \mathrm{~m}$ and the girths at breast height were more than $30 \mathrm{~cm}$ ). The locations of these plants in the garden are shown in Fig. 3 .

We used the information on terrain and buildings of surrounding area of Google Earth. When we make images with VRML, DEM of the garden were prepared.

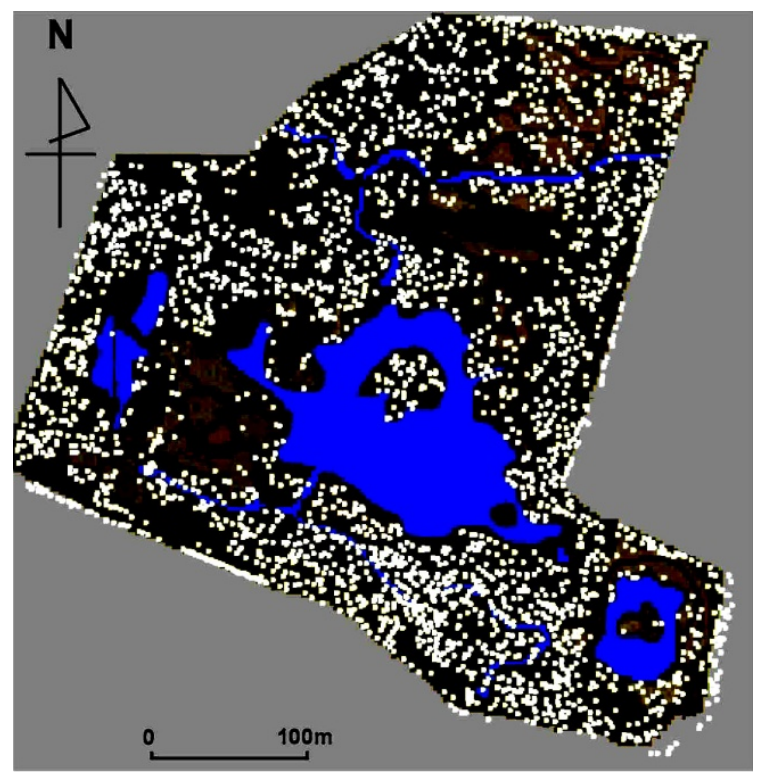

Fig. 3. Measured location of the plants in Koishikawa Korakuen Garden. White points indicate plants.

\subsection{Expression of trees with $K M L$}

Program of KML is more complicated than the program of VRML. KML is basically expressed with XML format. An example of trees by using billboard system in the KML is shown in Fig. 3 In Fig.3(a), structure of whole program is shown. At the first part, viewpoint is defined and expressions of trees continue. In this case, there are $\mathrm{n}$ trees.

In Fig 3(b), expression of one tree which made of two planes (first plane and second plane) is shown. The difference between first plane and second plane is just a direction of the plane express by " $<$ heading $>$ " node. When the white parts of the planes are made transparent by using the transparent png format, it seems like 3-D. Although this method is very simple to express a tree, it is effective method with minimum polygons. 


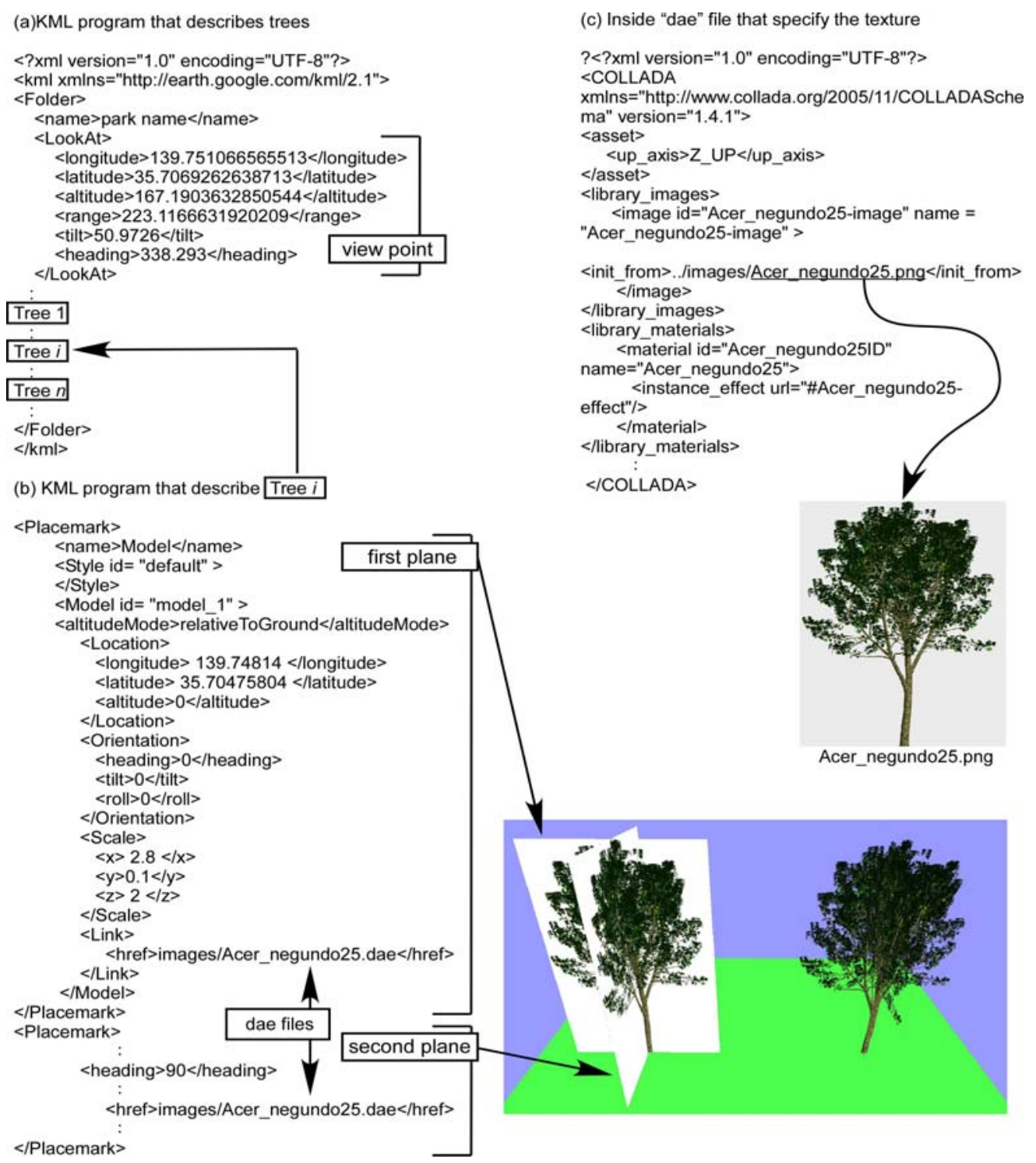

Fig. 4. Description of KLM file and DAE file for the visualization.

The actual texture file which is used in making the tree is defined in "dae" file. Inside of dae file is shown in Fig. 3(c) and COLLADA in XML format is used. In Fig. 3(c), the texture of "Acer_neugundo25.png" is specified and the actual image of the file is shown below the code. When we use $n$ texture files, $n$ dae files should be defined.

\section{RESULTS AND DISCUSSION}

\subsection{Simulation and Visualization of Japanese garden}

By using the developed landscape visualization system, a KML program was made from collected data and the performance of the system was evaluated. The simulated image was generally precise compared to the photograph or the real scenery.

In Fig. 5 the landscape of the Koishikawa Korakuen Garden was simulated on Google Earth and it is compared with the photograph shown in Fig. 5 (a).

Fig. 5 (b) is an image of the on Google Earth without vegetation and Fig. 5 (c) is an image with vegetation made with the system developed in this study. It is obvious that the image with the vegetation is more realistic than the image without vegetation. Buildings surrounding the garden are shown in three dimensional shape with the function of Google Earth. The image of Fig. 5 (c) with Google Earth is simulated the real situation shown in the photograph shown in Fig. (a). As a tool for the visualization and simulation of landscape, Google Earth indicated quite good performance.

Fig. 6 shows the comparison of the images with and without vegetation. It is obvious that the reality of the simulated landscape with vegetation in Fig. 6(b) is better than that without vegetation in Fig. 6(a) . On the ground level, the advantage of existence of vegetation is very important especially in walk -through simulation.

In the landscape design, landscape architects need to show their concepts of the design. Although simple billboard system 
is employed in this study, these pictures indicated that concept of the designed landscape can be effectively by the function of walk-though in the garden.

We proved that landscape design with Google Earth was possible and that the system can be used as a practical and low cost landscape design system

\subsection{Comparison with VRML}

Using Google Earth has some advantages compare to using VRML. When we use Google Earth, It is not necessary to prepare the terrain model (DEM). Background image of the model is also automatically made with Google Earth. In comparing the VRML image of Fig.7 with Fig. 5(c), advantage of using Google Earth is obvious.

Only deficiency of using Google Earth is network connection. To use the full function of Google Earth, network connection is indispensable. On the other hand, no internet connection is not necessary, when we make images with VRML.

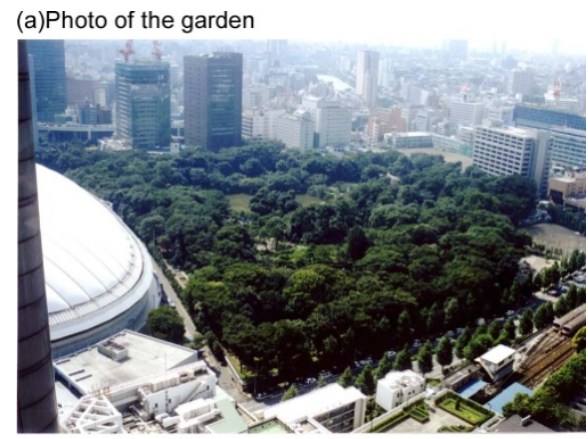

(b)Image of the Google Earth without vegetation

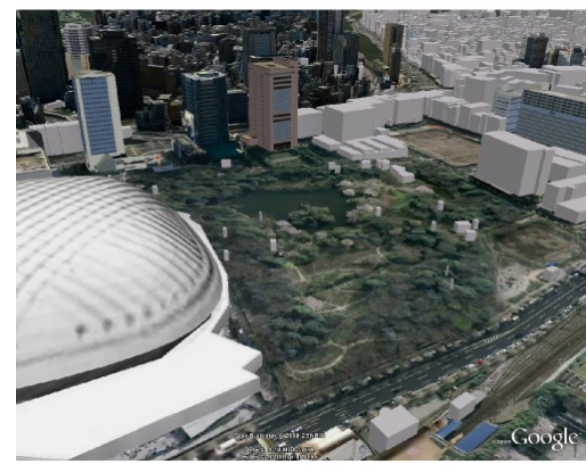

(c)Image of the Google Earth with vegetation

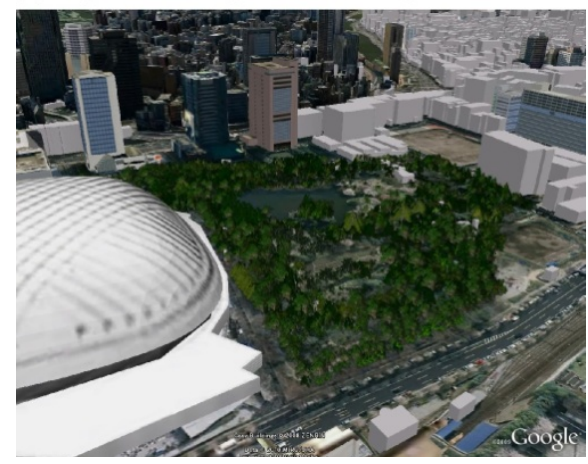

Fig. 5. Comparison of photo and Google Earth of the Koishikawa Korakuen Garden with and without vegetation.
(a)Image of the Google Earth without vegetation

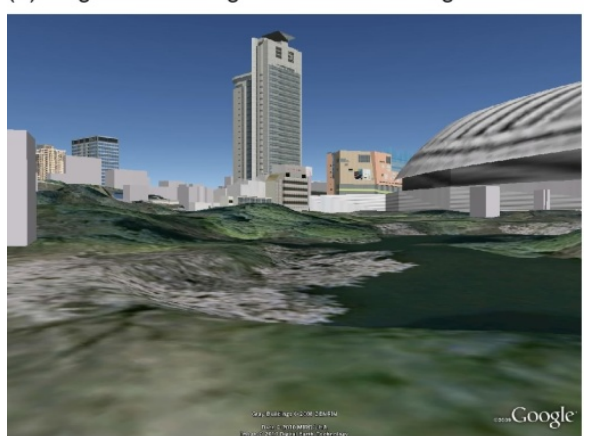

(b)Image of the Google Earth with vegetation

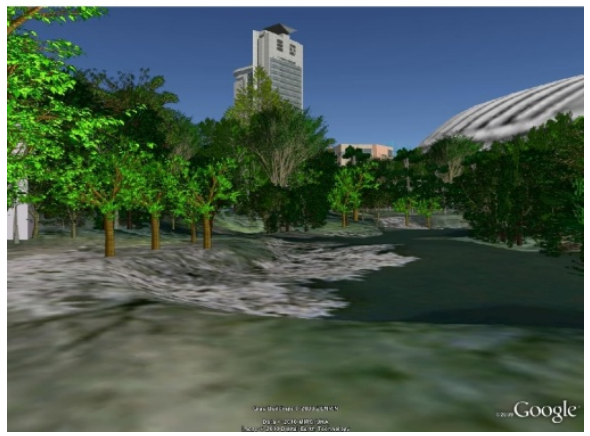

Fig. 6. Ground level images of Google Earth of the Koishikawa Korakuen Garden with and without vegetation.

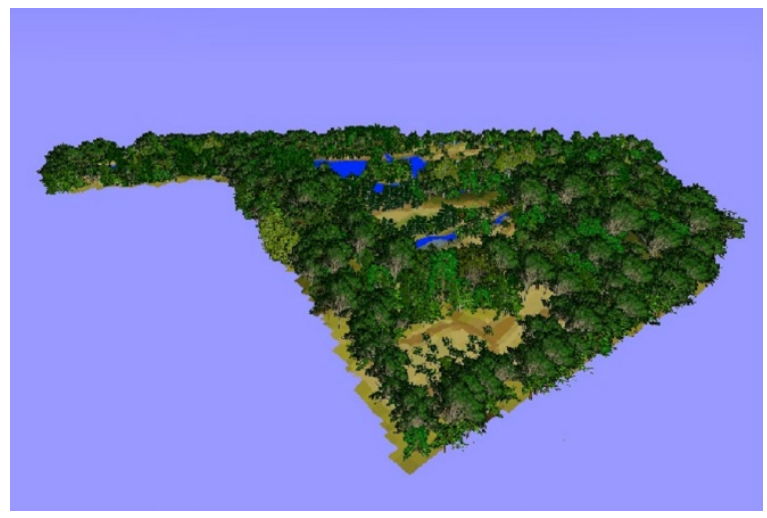

Fig. 7. VRML image of the Koishikawa Korakuen Garden. (Color Plate 3)

\section{CONCLUSIONS}

In this study, Google Earth and KML were used for developing landscape design system. With the system landscape visualization and simulation was proved to be possible. It can be used as a practical VR system for landscape design. Walk-through simulation in the garden was also possible. Because Google Earth is a freeware, the design system can be made with low cost.

\section{ACKNOWLEDGEMENTS}

We would like to thank Dr. Enmi Lim and Mr. Daisuke Kawashima, Chiba University for input the data and improving the system. 


\section{REFERENCES}

[1] I. D. Bishop, "Predicting movement choices in virtual environments", Landscape and Urban Planning, 56, 97- 106, 2001.

[2] P. De Reffye, C. Edelin, J. Francon, M. Jaeger and C. Puech, "Plant Models Faithful to Botanical Structure and Development", Computer Graphics, 22, 151-158, 1988.

[3] T. Honjo and E. Lim, "Visualization of Landscape by VRML system", Landscape and Urban Planning, 55, 175-183, 2001.

[4] E. Lim and T. Honjo, "Three-Dimensional Visualization Forest of Landscapes by VRML”, Landscape and Urban Planning, 63,175-186, 2003.

[5] E. Lim, K. Umeki and T. Honjo, “Application of Virtual Reality and Plant Modeling for Participation in Urban Planning and Design”, The International Journal of Virtual Reality, 8, 91-99. , 2009

[6] Y. Morimoto, "Computer Visualization of the Vegetation of Katsura Imperial Garden by a Plant Modeling and Visualization System”, Journal of the Japanese Institute of Landscape Architecture, 57(5), 113-120, 1993. (In Japanese with English summary)

[7] K. Umeki, E. Lim and T. Honjo, "A GIS-based simulation program to predict multi-species size-structure dynamics for natural forests in Hokkaido, northern Japan”, Ecological Informatics, 3, 218-227,2008

[8] Tokyo Metropolitan Government and Korakuen Stadium, Report on environmental and biological investigation of Koishikawa Korakuen in 1985, 1986. (In Japanese)

[9] K. Saito, Y. Kumagai, T. Honjo, Ishida, Y., Lecoustre, R. and De Reffye, P., "Photo-realistic Forest Landscape Simulation - Application of GIS and Plant Modeling Technique ”, Nicograph Paper Contest, 9, 226-236, 1993. (In Japanese with an English summary)

[10] O. Oliver Deussen and B. Lintermann, Digital Design of Nature: Computer Generated Plants and Organics, Springer, 295 pp, 2005.

[11] C. Gaucherel, N. Giboire, V. Viaud, T. Houet, J. Baudry and F. Burel, A domain specific language for patchy landscape modelling: The Brittany Agricultural Mosaic as A Case Study. Ecological Modelling. 194, p. 233-243, 2006.

[12] P. Paar, W. Rohricht, et al, Towards a planning support system for environmental design and agrienvironmental measures - the colorfields study, Journal of Environmental Management, 89, 234-244, 2008.

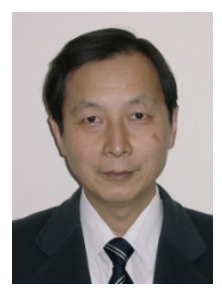

Tsuyoshi Honjo, PhD, is a professor at Graduate School of Horticulture at Chiba University, Japan. One of his interests is visualization of landscape by computer graphics. He is also interested in urban meteorology, especially the effect of urban vegetation and various area of computer application in agriculture..

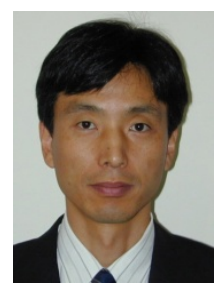

Kiyoshi Umeki, $\mathrm{PhD}$, is an associate professor at Graduate School of Horticulture at Chiba University, Japan. His main interest is in tree ecology and forest ecology. He is also interested in functional-structural tree models.

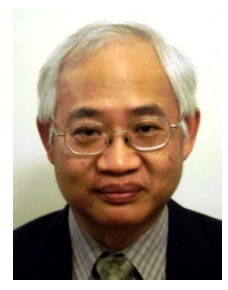

Dar-Hsiung Wang. PhD. is a senior scientist in Taiwan Forestry Research Institute. Taiwan. His main interest is in timber growth model and forest management. He is also interested in the landscape visualization models.

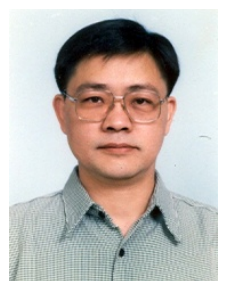

Ping-An Yang, PhD. is an assistant professor in Department of Leisure, Recreation and Tourism Management at Southern Taiwan University. Taiwan. His main interest is in environmental and landscape. He is also interested in forest landscape scenic assessment.

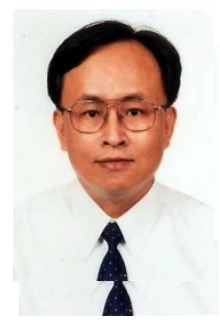

Han-Ching Hsieh, PhD, is an associate scientist at Taiwan Forestry Research Institute, Taiwan. His main interest is geographic information system and remote sensing in forest management and landscape ecology. $\mathrm{He}$ is also interested in 3D visualization techniques applied on forest landscape. 